\section{Comunicação Eletrônica: as transformações nas organizações}

\section{RESUMO}

As organizações passam por transformações de ordem diversas. No que tange à comunicação, a informatização está transformando a comunicação dirigida escrita impressa em dirigida escrita eletrônica. Seis empresas entrevistadas mostram a realidade dessa comunicação eletrônica, ressaltando que a mesma trouxe agilização, mas que ainda não descartaram totalmente a forma escrita impressa, acrescentando que, do ponto de vista das relações humanas, a forma eletrônica tem isolado as pessoas. Para essa nova forma de veicular, este trabalho propõe, no seu texto original, uma formatação padronizada desse tipo de comunicação aos seus usuários, pois o setor está carente e tem chamado tudo de "e-mail", por falta de conhecimento de como caracterizá-la.

\section{ABSTRACT}

The enterprises undergo different types of transformation. In terms of the written medium, the printed forms of communication are being replaced by the electronic one. Six entrerprises, which were interviewed about the reality of electronic communication, emphasized that it resulted in faster communication, but that it isolated people. In addition, they said that written, printed communication has not been abandoned yet. This work offers some standards to users of this new medium of communication, to compensate the absence of rules for this new form which people are generically calling of "messages by e-mail".

\section{PALAVRAS-CHAVE (KEY WORDS)}

- Comunicação eletrônica (Electronic communication) - Computador e organizações (Computer and organizations)

- Comunicação Impressa (Printed communication)

\section{Cleuza G. Gimenes Cesca}

Doutora em Ciências da Comunicação pela USP

\section{Introdução}

VÁRIOS SÃO OS FATOS que têm transformado a vida das organizações, levando-as à busca da modernização e competitividade. Esses fatos que estão redefinindo a vida empresarial podem ser identificados como a cultura organizacional que está mudando, e fazer essa transição causa traumatismos, insatisfações e desajustes; o meio ambiente é outro enfoque que teve de ser dado pelas organizações, visando administrar, para não chegar à controvérsia, que traz prejuízos de imagem e dividendos; a globalização que levou as organizações da competição com o vizinho, para uma competição mundial, com a qualidade desses grandes concorrente; as novas tecnologias que reduziram o quadro de recursos humanos, levaram todos a urgente reciclagem, em velocidade gigante; as terceirizações, não tão novas, mas com muita ênfase agora em época de qualidade total, gerou novos públicos e novas responsabilidades; os novos públicos, decorrentes das redefinições, trouxe terceirizados para dentro de seus espaços físicos, levou os seus para fora, alterou os tipos de vínculos empregatícios; a presença da mulher nas chefias, também trouxe dificuldades, ajustes, devido a própria cultura das organizações; as privatizações trouxeram mudanças de proprietários, fusões de culturas diferentes, demissões, novas contratações e todas as dificuldades de administrar esses fatos; a responsabilidade social levou as organizações a refletirem sobre a filantropia, muitas vezes utilizada para desviar a atenção de sua irresponsabilidade com outros segmentos, para a real responsabilidade social; a comunicação eletrônica que transformou grande parte da comunicação dirigida escrita impressa em eletrônica, ob- 
jeto de nossa pesquisa.

De acordo com Cesca (1995:28), a comunicação dirigida escrita tem por seus veículos a finalidade de transmitir ou conduzir informações para estabelecer comunicação limitada, orientada e freqüente com um número selecionado de pessoas homogêneas e conhecidas .

São esses veículos divididos, segundo Andrade (in Cesca-1995:29) em correspondência, mala direta, manuais, publicações, relatórios, periódicos, barra do hollerith, quadro de avisos, cartaz, caixa de sugestões.

\section{A comunicação eletrônica dos veículos dirigidos escritos impressos}

Cada veículo tem sua possibilidade de transformação eletrônica vinculada à sua característica e ao seu tipo de público de interesse (destinatário). Assim sendo,

\section{Mala Direta ( "Folder", Folheto, Panfleto, flyer)}

A forma impressa dessas comunicações escritas que visam divulgar produtos e serviços ainda permanecerão por muito tempo no mercado devido as dificuldades de se alcançar eletronicamente todos os públicos de interesse. Porém, todas essas formas podem ser remetidas de forma eletrônica. A vantagem da forma eletrônica sobre a impressa dessas mensagens é o baixo custo da produção e remessa.

\section{"News-Letters"}

Trata-se de uma publicação mais sofisticada da empresa para um determinado público de interesse. Esse veículo tem na forma eletrônica total aplicabilidade dada as características de seu destinatário.

\section{"Press-release"}

É a forma pela qual as organizações em geral enviam as suas notícias para a imprensa divulgar de forma gratuita, daí a necessidade de ser realmente notícia, isto é, uma informação que interesse ao público dos diversos veículos de comunicação.

Sua forma eletrônica está em pleno uso por meio dos serviços da internet, o que tem facilitado o trabalho de ambas as partes.

\section{"Teaser"}

São formas de despertar a curiosidade do público para um determinado assunto. Poderá ser em forma de texto ou frases em fases. Sua forma eletrônica é muito adequada para o público interno(intranet). Para divulgação de massa os "out-door" são mais eficientes.

\section{Boletim, Jornal e Revista}

São "house-organs" que variam de tamanho e conteúdo. A forma eletrônica é adequada principalmente para o público interno.

\section{Relatório Público Anual e Relatório Social}

É a prestação de contas da empresa para com seus públicos de interesse, de forma criativa. A forma impressa tem se constituído em verdadeiras obras de arte. Sua forma eletrônica pode ser feita também em CD-Rom, com grande facilidades.

\section{Livro de Empresa}

São peças produzidas em momentos marcantes de qualquer organização. Sua produção impressa tem sido primorosa nos últimos anos no Brasil. Eletronicamente podem ser feitos em CD-Rom e distribuídos ao públicos de interesse, principalmente das grandes organizações.

\section{Barra de "Hollerith"}

O demonstrativo de pagamento ou "hollerith", por suas características (demonstração dos dados relativos ao pagamento referente ao trabalho prestado), dá ao emissor a garantia da leitura da mensagem contida na barra.

Para transformar as mensagens impressas da barra, em mensagens eletrônicas, será apenas necessário que todos os funcionários tenham acesso a terminais in- 
formatizados. Limitará, contudo, o impacto e o interesse que o veículo "hollerith" proporciona. E, evidentemente, não chamará "Barra de "Hollerith", mas talvez, "mensagens", "fique atento", "conecte-se", "fique ligado" etc.

\section{Manual de Integração}

Sua finalidade é integrar o funcionário à organização onde atua. Nele está contido seus direitos e deveres. A forma impressa garante ao seu leitor o acesso a ele na empresa ou na residência com muita facilidade. Sua adaptação eletrônica (intranet) é muito adequada com a recomendação de que se trabalhe com menos texto, mais ilustrações e todos os setores da empresa estejam informatizados.

\section{Quadro de Avisos , Jornal Mural e Mural}

São formas de comunicação diferenciadas que poderão ter suas mensagens transmitidas de forma eletrônica (intranet - público interno e extranet- público misto). Diminuirá, pelo menos no início de sua implantação, o interesse, pois não possui a atração do convencional.

\section{Cartaz}

É um veículo eficiente de divulgação que poderá ser transformado em eletrônico com muita facilidade, passando naturalmente por uma adaptação para exercer a mesma atração do convencional.

\section{Caixa de Sugestões}

São formas de colher informações do público de interesse de qualquer organização. A convencional é realmente uma caixa em formado atrativo, na qual o interessado coloca a sua opinião escrita em formulário próprio.

$\mathrm{Na}$ forma eletrônica isso poderá ser feito por meio da internet/intranet/extranet, secretária eletrônica ou ainda outros equipamentos instalados no espaço físico desejado, para digitação por parte do interessado.

\section{Carta Comercial}

É um veículo de comunicação dirigida, formador de opinião pública favorável para qualquer organização. Requer, porém, que seja bem redigida para atingir esse objetivo. Para isso a criatividade deve ser abundante, sem se apegar a modelos de arquivos, pois cada pessoa física ou jurídica é um público, portanto, para cada um uma maneira de redigir. As cartas modernas estão despidas de elementos que no passado eram considerados importantes. Essa correspondência é muito adequada para a forma eletrônica, mas está sendo elaborada sem a preocupação com a forma utilizada quando impressa e que é uma norma para a sua redação. Na forma como está sendo feita assemelha-se com o memorando. Pode-se, no entanto, trabalhar essa correspondência via "e-mail" guardando todas as características da carta impressa, havendo somente nova forma para o endereçamento. Dependendo, porém, do destinatário só se poderá trabalhá-la impressa, com remessa via correio.

\section{Memorando}

É uma correspondência informal, dirigida apenas para o público interno. Sua informalidade não dá a liberdade para a utilização em seu texto de termos familiares.

Seu conteúdo é comercial, portanto, não se pode chegar a exageros de "um abraço" ou o formalismo de "atenciosamente".

É de todas as correspondências a que mais largamente pode ser utilizada eletronicamente. A sua simplicidade impressa é adaptada facilmente na intranet, pois é uma comunicação somente interna.

\section{Ofício}

É uma correspondência quase que exclusivamente utilizada pelo setor público, para a comunicação entre chefias e com o seu público externo. No setor privado, somente é utilizada quando este dirigir-se ao setor público. Seu conteúdo é formal, porém sem os exageros do passado.

Sua utilização eletrônica interna (in- 
tranet) dinamiza a comunicação, sendo aconselhável que se procure manter a estética do impresso, pois trata-se de uma correspondência mais formal. A menos que o setor público opte por abolir este tipo de correspondência, utilizando o memorando (e-mail formatado). Nos casos de grandes formalidades, exigências de cerimoniais, a forma impressa distribuída pessoalmente ou por correio não devem ser desprezadas.

A sugestão é que na forma eletrônica se mantenha a formatação impressa do corpo desse documento para se garantir a sua formalidade.

\section{Circular}

Sempre que se pretender fazer uma mesma comunicação para vários destinatários, usa-se esta correspondência que é escrita de forma genérica, com estética bloco-compacto. Dada a sua característica genérica, a adaptação na forma eletrônica transcorre com grande facilidade.

\section{Requerimento}

É um documento somente usado ao dirigir-se ao setor público, no qual o interessado, após se identificar e se qualificar, faz a sua solicitação à autoridade competente.

Por tratar-se de documento endereçado somente ao setor publico ou àqueles com características de público (ex: escolas), esses precisarão autorizar formal e publicamente que as pessoas interessadas em requerer algo o façam por forma eletrônica. Nessa forma não haverá necessidade de deixar longo espaço entre o vocativo e o corpo, evidentemente.

\section{Telegrama}

Essa forma de comunicação parece que permanecerá sempre impressa. Atinge a todos, independente da localização geográfica, condição social e econômica. Tem, ainda, uma característica que a eletrônica parece não permitir com facilidade a todos: o absoluto sigilo. Caso, porém, essa característica deixe de ser importante, ou a forma eletrônica também garanta esse sigilo, ou ainda todas as pessoas do planeta possuam seus endereços eletrônicos; então, assim sendo, essa comunicação será feita por "email".

\section{A realidade nas organizações}

Visando traçar um panorama da comunicação dirigida escrita impressa/eletrônica nas organizações, fez-se estudo de casos ouvindo seis empresas da cidade de CampinasSP e região. Essa pesquisa revelou os dados mostrados no Quadro I, da página 172, que permite visualizar como estão sendo produzidos esses veículos.

Os dados mostram que as organizações estão utilizando largamente a comunicação eletrônica, mas não eliminaram a forma impressa. Elas também informam que a forma eletrônica veio facilitar e agilizar a comunicação; que praticamente não reduziu recursos humanos, embora tenha exigido dele rápida reciclagem; mas isolou as pessoas.

Essa transformação na comunicação escrita é altamente significativa para a vida das organizações; há porém uma lacuna, que é a ausência da produção de material formatado padronizado, disponível para orientação dos usuários, material esse que nosso trabalho de pesquisa está também contemplando e pretende disponibilizar em publicação •

\section{Referências}

CESCA, Cleuza G.Gimenes. Comunicação Dirigida Escrita na Empresa -teoria e prática. $2^{\mathrm{a}}$ ed. São Paulo: Summus Editorial, 1995.

COHEN, Roger. Tudo que seus Gurus não the Contaram sobre Comunicação Empresarial. $3^{a}$ ed. São Paulo: Best Seler, 1988.

CAPRIOTTI, Paul . Planificación Estratégica de la Imagen Coorporativa. Barcelona: Ariel Comunicación, 1999. 


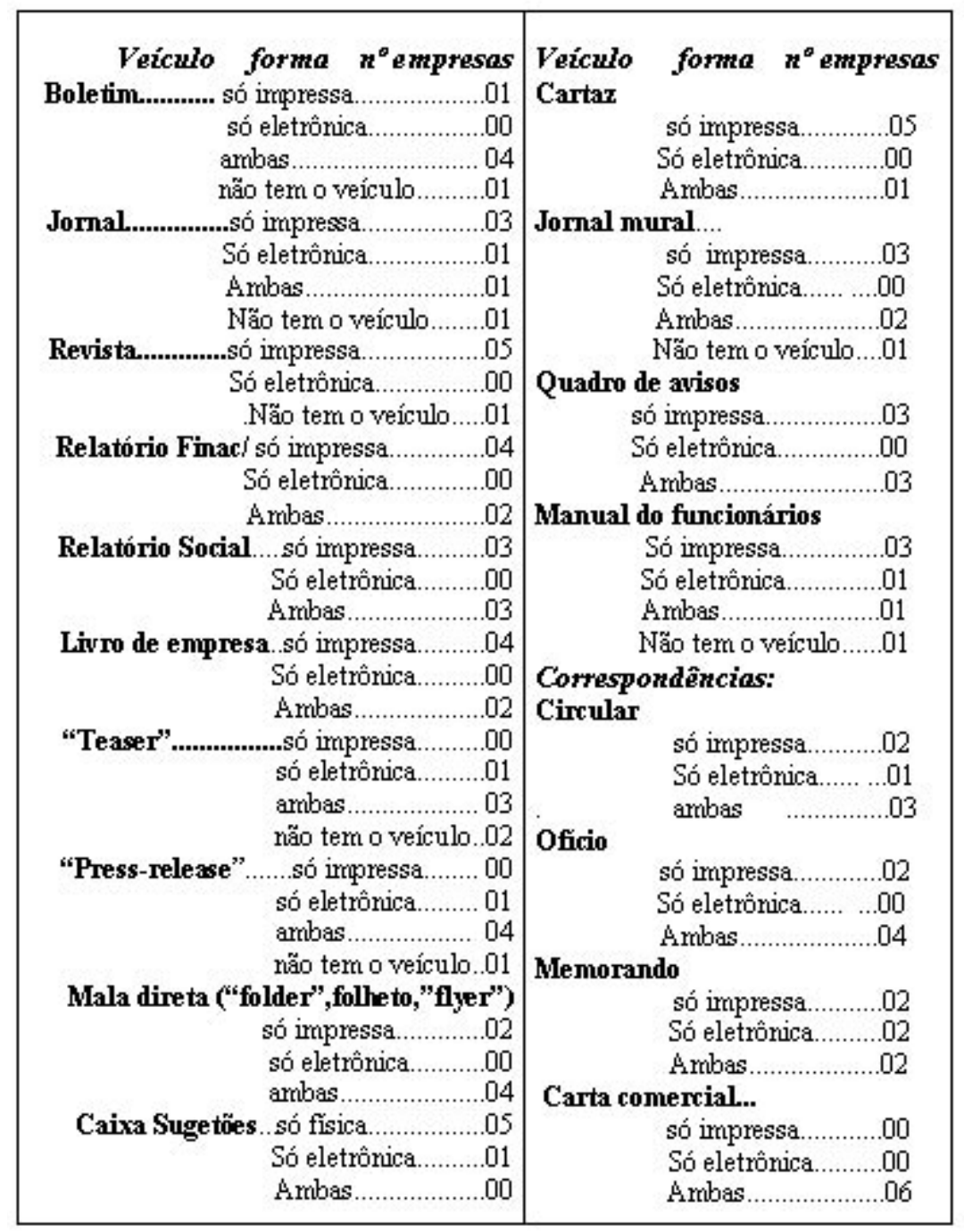

\section{Quadro I}

CERTO, Samuel C. e J.Paul Peter. Administração Estratégica. Trad.Flávio Deni Steffen. São Paulo: Makron Books, 1993.

CHAPELL, R.T. \& W.L.Read. Comunicação Interna na Empresa Moderna Trad. Edmond Jorge. Rio de Janeiro: Fórum, 1973.

CORNELLA, Alfons. Información Digital para la Empresa. Barcelona: Marcombo S/ ${ }^{\mathrm{a}}, 1996$.

CORRADO, Frank M. A Força da Comunicação. São Paulo: Makron Books,1994.

FREITAS, Maria Ester. Cultura Organizacional. São Paulo: Editora MaKron Books, 1991.

FLEURY, Maria Tereza e Rosa M.Fischer. Cultura e Poder nas Organizações. $2^{a}$ ed. São Paulo: Atlas, 1996.

KUNSCH, Margarida M.K. Planejamento de Relações Públicas na
Comunicação Integrada. $3^{\text {a }}$ ed. São Paulo: Summus Editorial, 1995.

Rel. Públicas e Modernidade- novos paradigmas na comunicação organizacional. São Paulo: Summus, 1997.

KOTLER, Philip. Maketing para o Século XXI. $5^{\mathrm{a}}$ ed. Tradução Cristina Bazán. São Paulo: Ed.Futura, 2000.

LAMPREIA, J.Martins. Comunicação Empresarial. Lisboa: Texto, 1992.

LLOYD, Herbert e Peter. Relações Públicas: as técnicas de comunicação no desenvolvimento das empresas. Lisboa: Presença, 1985.

MANUAL de redação da Presidência da República. Org. Gilberto Ferreira Mendes. Brasília, 1991. 
MOTTA, Paulo Roberto. Transformação Organizacional. São Paulo: Qualitymark, 1997.

RECORDER, Maria José, Ernest Abadal e Lluís Codina. Informação Eletrônica e Novas tecnologias. São Paulo: Summus, 1996.

REGO, Francisco Gaudêncio Torquato. Comunicação Empresarial - Comunicação Institucional. São Paulo: Summus, 1984.

SIMÕES, Roberto Porto. Relações Públicas-função politica. $3^{\mathrm{a}}$ ed. São Paulo: Summus Editorial, 1995

SQUIRRA, Sebastião C. de Moraes. O Século Dourado - a comunicação eletrônica nos EUA. São Paulo: Summus, 1996.

WILSON, Grahan. Fazendo Acontecer a Mudança. São Paulo: Editora Saraiva, 1996.

VALENTE, Célia e Walter Nori. Portas Abertas São Paulo: Ed. Bes Seller, 1990. 